\title{
¿Se puede pensar a la radio como un objeto socioantropológico?
}

Rosalía Winocur ${ }^{1}$

\begin{abstract}
$H$
ace poco más de seis años, cuando tuve que escoger un objeto de investigación para dar cuenta del papel de los medios en la transformación del espacio público y privado y su impacto en la formación de una cultura ciudadana, dudé entre la radio y la televisión. La televisión ya estaba legitimada como objeto antropológico, había bibliografía abundante, reciente y disponible. Por el contrario, a pesar de que la radio estaba presente en casi todos los hogares, se escuchaba en el automóvil, sonaba en las cantinas, los peseros, los puestos de periódicos, los talleres, las tiendas y los plantones en el Zócalo; seguía atrapada primordialmente en las redes de la crónica o el análisis ideológico. Al parecer, al igual que el cepillo de dientes, de tan popular se había vuelto invisible y pocos consideraban relevante entender su presencia en la vida cotidiana:
\end{abstract}

Un medio de comunicación con una presencia notable en la sociedad, con mucha fuerza, muy dinámico y muy sènsible a lo que sucede entre la población. Y sin embargo, es un soberano extraño (Gómez Vargas, 1994: 29).

Muchos de los textos sobre la radio que existen en México, se inscriben en el análisis del contenido de los mensajes y su historia de relación con el poder. La valiosa sistematización bibliográfica que realizó Pablo Arredondo (1991) es bastante ilustrativa sobre este punto. También se encuentran crónicas y testimonios sobre los primeros 40 años de la radio (Carrandi Ortíz, 1986; De María y Campos, 1938; Esquivel Puerto, 1970; Gamboa, 1949), ensayos sobre historia y política (Mejía Prieto, 1972; Felipe Gálvez, 1984; Fernández Christlieb, 1982; Sánchez Ruiz, 1984; Arredondo y Sánchez Ruiz, 1986),

1. Departamento de Educación y Comunicación, UAM-Xochimilco. Correo electrónico: winocur@cueyatl.uam.mx. 
textos sobre legislación (Fernández, 1960; Cremoux, 1989; Mejía, 1989; Paoli y Solís, 1985), comunicación popular y radio alternativa (Romo, 1990; Peppino Barale, 1998), y una variedad de encuestas encargadas por distintos organismos, empresas y radioemisoras con el objeto de conocer los hábitos del radioescucha y de medir sus preferencias con respecto a horarios y programación (CIRT, BIMSA, INRA, etc.). Sin embargo, son más escasos los ensayos que ubican a la radio como fenómeno cultural, no sólo vinculado a sus condiciones de producción y a la lógica del poder, sino también como espacio de identidad (Gómez Vargas, 1998), como memoria de "saberes y usos" (Mata, 1998: 93), como "palimpsesto" (Buenaventura, 1990), como fenómeno complejo y multidimensional que exige diversas lecturas analíticas (Sánchez Ruiz, 1992), como lugar de expresión de diversos usos sociales (Gómez Vargas, 1994) y, también, como espacio de recreación de las prácticas y discursos cotidianos de los ciudadanos en el contexto de la complejidad creciente de la vida en la ciudad (Martín-Barbero, 1993; Gómez Vargas, 1994).

La brecha que observa Cristina Mata (1998) entre la práctica y la enseñanza de la radio en las escuelas de Ciencias de la Comunicación, también se verifica a nivel de la producción teórica y empírica. A menudo aparece disociado el ensayo histórico de la crónica, la investigación de marketing de los estudios de carácter antropológico sobre los públicos, el análisis formal de los mensajes de los significados de las prácticas y discursos cotidianos. Y así podríamos seguir planteando dicotomías. Esto es más evidente si se tiene en cuenta que la bibliografía sobre televisión en México (Orozco, 1991, 1992a, 1992b, 1994; González, 1994) desde hace dos décadas refleja la superación del enfoque maquiavélico asignado al papel de los medios en el decenio de 1970, y sitúa la comprensión de su lógica en las mediaciones sociales y culturales, y en la apropiación diferenciada de los mensajes en una perspectiva antropológica de la recepción. ${ }^{2}$

\section{El arribo de la antropología al estudio de los públicos}

En una oportunidad mi hijo Javier me hizo la siguiente adivinanza: "Mamá, ¿qué tienen en común una familia, una estufa y un avión?" Le contesté que no sabía, y él me dijo: "La estufa y el avión tienen piloto." "Pero, ¿y la

2. En América Latina existen un conjunto de revistas que han sido claves para mostrar estos cambios. Por citar algunas, Dia-logos de la Comunicación, editada por la Felafacs, particularmente la línea editorial de los últimos diez años; Perfiles Latinoamericanos, núm. 9, diciembre de 1996, editada por Flacso México, dedicada a los medios de comunicación; Culturas Contemporáneas, editada en Colima; Versión, de la UAM-Xochimilco; Comunicación y Sociedad, editada por el ITESO, en Guadalajara, etcétera. 
familia?", repliqué. "Bien, gracias", respondió mi hijo en tono de burla. Creo que este acertijo es una buena metáfora de cómo estaban planteados los estudios de comunicación hasta principios del decenio de 1980 . Hace poco menos de 20 años, frente a la pregunta: ¿Qué tienen en común los medios, la familia y el ámbito doméstico?, se ensayaban múltiples respuestas acerca de la relación del mensaje y su impacto en los públicos, pero, iy la familia?: bien, gracias. A pesar de que casi todo el consumo se produce en el ámbito doméstico, la familia no constituía un referente para pensar la relación con los medios.

El famoso esquema: fuente-emisor-mensaje-receptor-destinatario dominó el panorama de los estudios de comunicación hasta el decenio de 1980, cuando se comienzan a cuestionar sus premisas epistemológicas. Armand Mattelart (1987), partiendo de la crítica al pensamiento lineal y al enfoque mecanicista de lo social, desarrolla un nuevo marco conceptual cuyas principales coordenadas son la recuperación de la perspectiva del sujeto en la comunicación, el replanteamiento de las relaciones entre intelectuales y cultura mediática y las nuevas lógicas del actor transnacional (Martín-Barbero, 1997). La revaloración del sujeto también se expresa en los estudios sobre la comunicación política, donde surgen interrogantes sobre el papel de la sociedad civil y de la ciudadanía en la construcción cotidiana de la democracia, y sobre la actividad del receptor en su relación con los medios:

Frente al racionalismo frankfurtiano y el mecanicismo psicologista del análisis de los efectos, se rescata el carácter complejo y creativo de la recepción: lugar denso de mediaciones, conflictos y reapropiaciones, de producción oculta en el consumo y la vida cotidiana. Pero este rescate en ningún modo puede significar desconocimiento de la desigualdad del intercambio en que opera la comunicación mediática [...] La rehabilitación del sujeto en la recepción ha puesto en primer plano la existencia en nuestra sociedad de matices y formas culturales distintas de la hegemónica (Martín-Barbero, 1997: 10).

En los últimos 20 años, en Estados Unidos, Europa y América Latina han proliferado una serie de estudios e investigaciones sobre la televisión realizados desde una perspectiva antropológica y hermenéutica, que marcaron una ruptura fundamental respecto de las dos grandes tradiciones en el estudio de los públicos: la indagación acerca de los efectos de los mensajes sobre los públicos tanto en su vertiente ideológica como conductista. La revisión primero, y el abandono luego, del concepto tradicional de audiencia compuesta por una masa de individuos pasivos devorando "mensajes" y reaccionando automáticamente frente al consumo, se vincula con una reflexión de carácter interdisciplinario acerca del papel de los medios en la vida contemporánea: 
La globalización, la cuestión transnacional, desbordó los alcances de la teoría del imperialismo obligando a pensar una trama nueva de territorios y de actores, de contradicciones y conflictos. El desplazamiento se traduce en un nuevo modo de relación con las disciplinas sociales por apropiaciones: desde la comunicación se trabajan procesos y dimensiones que incorporan preguntas y saberes históricos, antropológicos, semióticos, estéticos, al mismo tiempo que la sociología, la antropología y la ciencia política se empiezan a hacer cargo, ya no de forma marginal, de los medios y los modos como operan las industrias culturales (Martín-Barbero, 1997: 15).

Junto con la aceptación de que la recepción es parte de la esfera compleja, contradictoria, multidimensional, de la vida cotidiana, y el reconocimiento de las mediaciones culturales (Martín-Barbero, 1993; Orozco, 1994; Mata, 1992), se legitimaron en América Latina los métodos antropológicos para estudiar la complejidad de estos vínculos. El reconocimiento de un proceso de selección y apropiación diferenciado del contenido de los mensajes llevó a incorporar en el análisis de la recepción la etnografía del público y de los medios (González, 1994). El enfoque etnográfico resultó más apto para estudiar la circulación y la apropiación de los mensajes:

El objetivo era abrir el camino hacia un modo de pensamiento menos determinista respecto de algunas cuestiones: tomar posición políticamente contra la creciente comercialización de la producción y de la difusión televisadas no debería, como a menudo ocurre, excluir el conocimiento, a un nivel cultural, del placer real que sienten los espectadores frente al material mediático producido comercialmente -este reconocimiento demanda una explicación: la de los parámetros textuales y socioculturales de ese placer (Ang, 1997: 85-86).

La importancia de convivir con los medios supera en mucho a la de consumir sus contenidos. Mirar televisión o escuchar radio son situaciones que remiten a una multiplicidad de prácticas y experiencias situadas en diversos contextos. En esta perspectiva los públicos pueden ser pensados en familias, grupos, instituciones que interactúan simbólicamente con los medios en espacios social y culturalmente diferenciados. Estas interacciones se producen a partir de mediaciones, entendidas como "proceso estructurante que configura y reconfigura tanto la interacción de los miembros de la audiencia con los medios, como la creación por parte de ellos del sentido de esa interacción" (Orozco, 1994: 74).

Esto también implica que los gustos y hábitos como factores de explicación omnicomprensivos de la relación con los medios dejen de tener una importancia central en la caracterización de los públicos y sean reconstruidos en el marco de prácticas y sistemas de representaciones más amplios vincula- 
dos al conjunto de instituciones significativas en la vida cotidiana, particularmente la familia:

Las relaciones que la definen, los mitos, los relatos y valores que la sostienen, los conflictos o las crisis que la amenazan, brindan uno de los ambientes sociales básicos donde los individuos se debaten, día por día, con los problemas de la vida cotidiana. Así, cuando el consumo de medios se realiza en la familia, ello ocurre en una situación social compleja donde se expresan (a través de los variados subsistemas de relaciones conyugales, parentales o fraternales y a través de las relaciones que los miembros de las familias mantienen entre sí y con el mundo exterior) diferentes pautas de cohesión y disgregación, de autoridad y sumisión, de libertad y constreñimiento (Silverstone, 1996: 64).

Cuando delimitamos un problema de investigación, ya no basta con tener en cuenta el contexto de recepción o la relación con la dinámica familiar, sino que es necesario concebirlo en términos más radicales: la relación con los medios ocurre y transcurre en la vida cotidiana y esto tiene consecuencias fundamentales en el momento de concebir nuestro objeto de estudio.

Sin lugar a dudas, la etnografía de los públicos profundizó y reorientó la comprensión de la dinámica del consumo de los medios; sin embargo muchas de ellas, en el marco de los enfoques denominados de "usos y gratificaciones" (Morley, 1996), aislaron el estudio de las prácticas cotidianas de las condiciones de producción de los discursos mediáticos y su capacidad para estructurar el campo de la circulación y el consumo:

Los públicos pueden ser activos de muchas maneras en la utilización e interpretación de los medios, pero sería ingenuamente optimista confundir su actividad con un poder efectivo. De hecho, los públicos no disponen de ningún control sobre los medios a un nivel estructural o institucional duradero (Ang, 1997: 91).

La sobrevaloración de la autonomía de las audiencias en la selección y apropiación de los mensajes llevó a algunos investigadores a exagerar su capacidad de resistencia frente a los mensajes y, en consecuencia, a subestimar el papel de los medios en la estructuración del consumo:

Tan pronto como se reubica esta diada en un contexto más vasto, se observa que el encuentro entre el texto y su lector no se hace en el vacio; que está dominado por estructuras de poder. Poder que se deriva del hecho de que los espectadores pertenecen a públicos y que esos públicos están construidos. Poder que se deriva también del hecho de que el encuentro entre un texto y su lector jamás es inaugural. El texto de una emisión o de un programa ya ha sido leído, tratado por un conjunto de instituciones interpretativas que van desde la crítica hasta los anuncios publicitarios pasando por los esquemas de programación (Dayan, 1997: 18). 
El reconocimiento del poder de los medios en la organización simbólica del consumo nos obliga a pensar inevitablemente el problema de la ideología: ¿qué papel juega y de qué modo se manifiesta en el encuentro entre el texto y el lector?

\section{La reubicación del papel de la ideología: lecturas ideológicas versus lecturas preferenciales}

La hipótesis fundamental sobre el papel de las industrias culturales manejada por la escuela de Frankfurt condujo a tomar a la ideología como la única clave para comprender el problema del significado en el consumo, al punto que, durante mucho tiempo, lo cultural y lo ideológico han tendido a confundirse. Aunque estos estudios han realizado aportes fundamentales para comprender el papel de los medios en la construcción de la hegemonía y los mecanismos discursivos e institucionales mediante los cuales reproducen esta función, pecan de reduccionismo cuando conciben los procesos de consumo cultural sólo en su dimensión de reproducción ideológica, negando la complejidad de los intercambios simbólicos y distorsionando considerablemente la interpretación sobre lo que en realidad ocurre en el encuentro entre el texto y el lector. Desde que Verón (1983) introdujo la distinción entre producción y reconocimiento, ha insistido en el desfase entre ambos polos y en la "indeterminación relativa" que caracteriza la circulación discursiva: "no linealidad de la comunicación, una gramática de producción, varias gramáticas de reconocimiento. Del análisis de un discurso en producción no se pueden deducir sus efectos en recepción" (1995: 20). En esta perspectiva, se concibe el mensaje como una polisemia estructurada que puede ser decodificada de diversas formas: "las audiencias leen y dan sentido de manera diferente a los mensajes transmitidos y operan según estos sentidos en el contexto de su propia situación y experiencia" (Morley, 1996: 126). Esto implica que no habrá necesariamente ajuste o transparencia entre los extremos de la codificación y la decodificación dentro de la cadena comunicativa (Hall, 1974), más aún, se puede afirmar que esta ásimetría es constitutiva, ya que las condiciones de producción de un discurso jamás son equiparables a sus condiciones de recepción (Verón, 1983). Si las condiciones de producción y recepción no son equiparables, el sentido del texto se debe reconstruir en el espacio de articulación que se genera entre el mensaje y el conjunto de los discursos que lo interpelan en una circunstancia particular. Un encuentro que puede reestructurar en distintas direcciones los significados de ambos, según los conocimientos, prejuicios y resistencias que el lector aporte al texto. 
Los aportes del Centro de Estudios Culturales Contemporáneos de Birmingham, fundamentalmente los de Stuart Hall (1989), ayudaron a situar el problema de la ideología en la articulación de ciertas lecturas preferenciales o dominantes con la apropiación diferenciada y selectiva de distintos grupos en diversos contextos socioculturales que refuerzan las relaciones de poder económico, político y social. El concepto de lectura preferencial imbrica desde el punto de vista teórico la cuestión de la hegemonía con el de las apropiaciones diferenciadas de los públicos. Esto implica que "las audiencias producen sentidos, pero tienen que trabajar con un material que ya ha sido preseleccionado y organizado de manera específica por los productores" (Morley, 1996: 176). Sin embargo, este concepto presenta algunas dificultades: en primer término fue pensado para la lectura de noticias, y las categorías utilizadas no siempre se pueden generalizar a otros textos como las telenovelas, los programas de entretenimientos o los consultorios sentimentales:

El intento de trasladar el concepto al mundo de la ficción, y considerar entonces equivalentes la "lectura preferencial" y la "clausura narrativa" (o la jerarquía del discurso), siempre nos hace correr el riesgo de reducir el texto de ficción a un mero vehículo de una proposición sustantiva trivial que así se pudiera rotular de ideológica (Morley, 1996: 177).

En segundo término, no queda claro si las lecturas preferenciales son propiedad de los textos o de los públicos, es decir, "ise vuelven preferenciales a partir de las condiciones que fija el texto, o de los esquemas interpretativos utilizados por los públicos?" (Morley, 1996). El concepto de lectura preferencial tiene valor analítico no como un modo determinista de establecer interpretaciones dominantes, dejando de lado otras lecturas posibles, sino como una forma de explicar que en ciertas condiciones y en determinados contextos, un texto tiende a ser leído de un modo particular por el auditorio, o por algunos de sus segmentos (1996: 128). La posibilidad de que un programa logre transmitir el sentido dominante propuesto por el discurso dependerá de que encuentre un público que comparta códigos e ideologías válidos en otros ámbitos institucionales que sean coherentes con los del discurso del programa. Pero también puede ocurrir que un mismo grupo en algunas situaciones comparta los códigos del programa y en otros no, que de una manera general se identifique con la ideología propuesta, pero que según el espacio, los interlocutores o las circunstancias, su identificación se desdibuje, entre en contradicción y/o en negociación con otros marcos interpretativos, o simplemente sea desechada. Considerar como punto de partida las decodificaciones individuales en su contexto sociocultural no supone que el pensamiento y la acción individuales estén determinados rígidamente por la pertenencia de clase: 
No estamos obligados a plantear esta situación como un problema disyuntivo: es decir que la decodificación sea o bien infinitamente variable (tantas decodificaciones como individuos) o bien directamente predecible en el caso de todos los miembros de una clase social dada (como una consecuencia directa y determinada de su posición social). Más bien debemos comprender la relación que existe entre las dos dimensiones, o sea: entender la experiencia y la respuesta individual y variada tal como se da en un contexto social particular en virtud de los recursos culturales de que se dispone en dicho contexto (Morley, 1996: 131).

En síntesis, nuestro enfoque comparte las siguientes premisas respecto a las formas de codificación de los mensajes (Morley, 1996: 174; Lull, 1997: 226):

a) El mismo acontecimiento se puede codificar de diversas formas.

b) El mensaje puede provocar más de una lectura potencial. Los mensajes proponen ciertas lecturas en lugar de otras, pero no pueden cerrar el marco de su interpretación; los mensajes codificados de una forma siempre pueden leerse de un modo diferente.

c) El sentido o la lectura del programa que genere el espectador dependerá de los códigos de interpretación que el espectador aporte al texto:

Si pretendemos explicar la compleja naturaleza interactiva y a menudo contradictoria de los medios, la comunicación y la cultura, debemos reconocer tres axiomas fundamentales: la estructura no está fija ni es determinante; los mensajes simbólicos son polisémicos y multisémicos, y los actores sociales interpretan y usan su entorno simbólico de maneras que representan sus intereses personales, sociales y culturales (Lull, 1997: 226).

Esto implica que el sentido de un texto no depende de la intención de su autor al producirlo ni la de los sujetos al decodificarlo. Como apunta Hall (1974):

La conciencia del emisor es un ámbito que debemos estudiar porque el terreno de la intención existe no como el origen de la nada, sino precisamente como ese terreno intencional producido por el campo de la ideología que está [...] fuera de la intención (citado por Morley, 1996: 174).

El desafío reside en poder articular analíticamente la capacidad que tienen los espectadores de construir sus propias significaciones en el ámbito de sus culturas e identidades locales, con las lecturas dominantes que les imponen los flujos de imágenes distribuidos por las industrias culturales transnacionales (Borja y Castells, 1998). 


\section{¿Prácticas de recepción o de consumo?}

En el marco de reflexión propuesto nos preguntamos si tiene sentido seguir hablando de recepción para explicar la complejidad del vínculo que se produce en el intercambio cotidiano de los públicos y los medios. Este concepto, que se deriva del modelo de transmisión lineal de la comunicación, ha quedado demasiado pegado a la tradición experimental de los estudios e investigaciones sobre medios, al punto de que, si uno no agrega el adjetivo de activa, se da por entendido que recepción es sinónimo de pasividad. Por estas razones nos parece más apropiado hablar de prácticas de consumo doméstico, lo cual también requiere de ciertas precisiones conceptuales.

El consumo sirve para pensar, sostiene García Canclini (1995: 41), y con ello hace referencia a que no existe un acto de consumo, por modesto o suntuario que sea, que no lleve implícito un universo de sentidos, que lógicamente cambian de una cultura a otra, e incluso de un grupo social a otro; lo que en ciertas culturas puede considerarse un derroche, en otras adquiere sentido ritual. El consumo también se vincula al capital cultural de distintos grupos (Bourdieu, 1988); determinadas adquisiciones, como la de una obra de arte, en algunos segmentos sociales constituyen un símbolo de prestigio o apreciación estética, y en otros ni siquiera forman parte del repertorio de objetos apreciados, es decir, que valga la pena tenerlos aunque no se puedan comprar. El consumo puede entenderse como un proceso ritual (Douglas e Isherwood, 1990), en el sentido en que comprar, utilizar, adornar, o distribuir los objetos tanto en los espacios públicos como en los privados ayuda a establecer cierto orden y control sobre el flujo de significados, a distinguir unos espacios de otros y a explicar y mostrar por qué las cosas deben ser de una forma y no de otra en distintos momentos y realidades culturales $e$ históricos:

Lo que aparece en los medios de comunicación masiva es útil, no sólo porque es de fácil acceso y resulta atrayente. Los propios intereses de los consumidores de los medios, puestos en juego en las circunstancias y lugares de reunión donde se reciben los mensajes (los innumerables contextos microsociales) también ejercen una gran influencia en el modo en que se interpreta y se utiliza la imaginería de los medios (Lull, 1997: 86).

En las prácticas de consumo también se construyen los nuevos sentidos de la ciudadanía (García Canclini, 1995). Esta posición parte de la premisa de reconocer la mediación que introduce el mercado y los procesos de consumo, particularmente el consumo de los medios masivos, en la reconfiguración de los significados tradicionales de la ciudadanía: 
La aproximación de la ciudadanía, la comunicación masiva y el consumo, tienen, entre otros fines, reconocer estos nuevos escenarios de constitución de lo público y mostrar que para vivir en sociedades democráticas es indispensable aceptar que el mercado de opiniones ciudadanas incluye tanta variedad y disonancia como el mercado de la ropa y los entretenimientos (1995: 30).

En esta construcción, los medios asumen la fragmentación de la ciudadanía y se ofrecen como mediadores "de la heterogénea trama de imaginarios de identidad de las ciudades, regiones, espacios locales y barriales" (MartínBarbero, 1999: 43). Y es precisamente en esta mediación donde contribuyen a resignificar el ejercicio y la representación de la ciudadanía, poniendo en circulación toda clase de asuntos del orden público y privado, cambiando el sentido de sus ámbitos de referencia, tendiendo puentes imaginarios con las autoridades, reubicando lo global o proyectando lo local fuera de sus espacios concretos, en fin, llevando y trayendo información de la escena pública al hogar y del hogar a la pantalla. De ahí la relevancia del ámbito doméstico como unidad de observación y análisis, ya que constituye el espacio físico y simbólico cotidiano por excelencia donde se articulan, a través del consumo, las transformaciones en la esfera de lo público y la emergencia de la ciudadanía como exigencia de visibilidad y reconocimiento de necesidades cotidianas vinculadas no sólo a las prácticas políticas, sino también a la negociación conflictiva del uso de los espacios en la ciudad, al acceso y la calidad de los servicios, y a la reivindicación de la diferencia.

\section{Una propuesta para estudiar la radio: diseño metodológico y organización del trabajo de campo}

El diseño metodológico que se reseñará a continuación corresponde a una investigación que se planteó los siguientes objetivos:

1. Investigar el proceso de especialización de la radio como manifestación de cultura ciudadana, a partir de entender cómo contribuyó históricamente a plasmar el sentido de la vida urbana, y generar un imaginario sobre la ciudad.

2. Reconstruir cómo la experiencia privada y fragmentada de los ciudadanos cristaliza públicamente en la radio y se instituye como esfera pública, interpretando y reinterpretando los usos, las interacciones y la ritualidad de diversos sectores sociales.

3. Estudiar cuáles son las prácticas y sentidos que determinan los usos y modos de apropiación de los discursos radiales en la vida cotidiana de distintos grupos sociales y culturales en la Ciudad de México. 
El problema expuesto exigía investigar, por una parte, la dinámica y el sentido de los intercambios entre la familia y el medio en el contexto del hogar $y$, por otra, la lógica de producción del mensaje radial en su propio ámbito de sentido: el discurso de productores y conductores de radio.

Para el primer aspecto diseñamos una estrategia metodológica que nos permitió indagar:

a) La organización cotidiana de las prácticas del consumo doméstico.

b) La apropiación, selección y circulación diferenciada de los mensajes entre los miembros de la familia, sus vecinos y amistades.

c) La inclusión de sus necesidades de participación y reconocimiento en la esfera pública mediática.

El proceso de investigación de este problema se dividió en tres momentos: una etapa exploratoria y dos periodos de trabajo de campo. En la etapa exploratoria se realizaron observaciones en una variedad de situaciones en que habitualmente se escucha la radio en el espacio público: el autobús, las cantinas, las oficinas, los puestos de periódicos, los talleres, etcétera. Todos estos contextos de relación con el medio mostraron algo en común: escuchar la radio (a diferencia de lo que ocurría en el pasado) implica un acto de privatización de su consumo, aunque el aparato esté ubicado en un lugar público. El caso más sintomático fue el de los autobuses. El conductor fue el único que pudo reconocer la estación en que estaba sintonizado el radio. Aunque muchos de los pasajeros compartían sus preferencias musicales, e incluso escuchaban la misma emisora en sus casas, no prestaban atención a la radio en el transporte. Esta suposición se confirmó con los resultados que arrojó una encuesta sobre consumo cultural en la Ciudad de México. ${ }^{3} \mathrm{La}$ mayoría declaró que el lugar donde escuchaba la radio habitualmente era su casa: dato especialmente significativo si tenemos en cuenta que $56.7 \%$ de los habitantes del Distrito Federal realiza al menos dos viajes por día de una hora y media de duración en promedio, utilizando el transporte público (taxis, autobuses, microbuses, metro) ${ }^{4}$ donde está encendido el radio en la mayoría de los casos. Esta exposición al medio prácticamente no fue mencionada, lo cual implica que el único consumo reconocido es aquel que se practica en el ámbito privado - la casa o el automóvil-, utilizando un aparato propio donde se puede seleccionar la programación de su agrado. El segundo dato de interés que arrojó la encuesta lo constituye el hecho de que no se perciba el acto de escuchar radio como una actividad del tiempo libre, a pesar de que $100 \%$ declaró que posee al menos un aparato de radio, que lo escucha en

3. Encuesta realizada por el periódico Reforma. Véase "Consumo cultural y medios en la Ciudad de México", 24 de enero de 1996, p. 10C.

4. Datos de la encuesta: Origen y destino de los viajes de los residentes del área metropolitana de la Ciudad de México. INEGI-DDF-Estado de México, 1994, pp. 53 y 98. 
promedio 6.4 días a la semana, y que $56 \%$ se expone cinco horas diarias. El acto de escuchar la radio no se conceptualiza como ocio, porque su consumo está incorporado y asociado simbólicamente a la organización de las rutinas cotidianas, y en ese sentido no representa una actividad diferenciada y programada que se practique en el tiempo libre.

A partir de las observaciones reseñadas, resolvimos destacar como unidad de observación y análisis el ámbito doméstico. Para llevar a cabo el trabajo de campo se diseñaron dos estrategias de exploración: una pauta de observación de los hogares y una guía de entrevista en profundidad para algunos miembros de las familias estudiadas, con el objeto de enriquecer y cruzar la información obtenida en los registros. ${ }^{5}$

Para resolver las condiciones del trabajo etnográfico, optamos por buscar entre nuestros alumnos de la carrera de Comunicación Social de la Universidad Autónoma Metropolitana las familias de sectores medios y medio bajos. Dado el carácter público y gratuito de la universidad esto fue relativamente sencillo. Por su parte, los hogares de estratos altos fueron escogidos entre los alumnos de una universidad privada de élite.

Se capacitó a los estudiantes para que, durante las dos semanas seleccionadas, observaran la interacción de sus familias con la radio en las siguientes situaciones: el noticiero en el momento del desayuno, los programas de la mañana mientras se realizan las tareas domésticas, y las rutinas en el automóvil, en tanto extensión del ámbito privado. ${ }^{6}$

Al diseñar esta estrategia, asumimos el sesgo y las lagunas que necesariamente tendría la información: por una parte, la autocensura consciente e inconsciente que el observador aplicaría en sus observaciones; y, por otra, la mirada diferida sobre los ámbitos de estudio. Escogimos esta opción porque aun en el caso ideal de contar con la posibilidad de observar "directamente" los 18 hogares, habríamos necesitado mucho tiempo para que nuestra presen-

5. El material etnográfico utilizado en el análisis proviene de dos investigaciones diferentes. El primero se ubica en el año 1994, dentro de un estudio sobre las prácticas e interacciones con los medios en el ámbito doméstico. Véase Vázquez y Winocur, 1995. El segundo se llevó a cabo dentro del proyecto auspiciado por el Consejo Nacional de Ciencia y Tecnología (Conacyt): "Radio y participación ciudadana en la ciudad de México", entre 1996 y 1998.

6. La estrategia de capacitación consistió en realizar una serie de ejercicios y dinámicas grupales con el objeto de entrenarlos en las técnicas de registro y provocarles extrañamiento sobre sus prácticas cotidianas. Se les pidió que realizaran por escrito una descripción de todo lo que ocurría en la escena familiar (desplazamientos, diálogos, actividades, interacciones, gestos, movimientos, recorridos, etc.) en relación con la radio, colocando entre paréntesis sus impresiones sobre las escenas familiares, o datos que nos permitieran contextualizar ciertas actitudes o conductas aparentemente sin sentido. El hecho de que la mayoría de los observadores fueran estudiantes de Comunicación facilitó bastante la labor del registro, ya que sus parientes están acostumbrados a verlos trabajar de distintas formas con los medios y aceptaron con naturalidad el registro. 
cia fuera aceptada con "naturalidad". Esto es particularmente evidente si tenemos en cuenta que el ámbito de observación es el contexto doméstico, lo cual implica que aun extremando los cuidados, es imposible no provocar una alteración de los ritmos y organización doméstica, además de una molesta intromisión en la intimidad familiar. En cualquier caso, el acceso a la vida privada es relativo; siempre habrá sectores del hogar prohibidos para el extraño y una parte de la vida doméstica nunca se manifestará en presencia de alguien ajeno a la familia. Por el contrario, los estudiantes reconstruyeron en muy poco tiempo dinámicas familiares y prácticas de relación con los medios que de otro modo hubiera sido muy difícil documentar. Sus registros permitieron caracterizar los estilos de consumo, apropiación y resignificación de los mensajes mediáticos en cada grupo de familias. Incluso lo que omitieron, censuraron o expresaron con lujo de detalles se convirtió en información valiosa para diferenciar los patrones de interacción de cada segmento sociocultural. $^{7}$

En conjunto, el material resultó rico y sugerente, lo cual ayudó a problematizar algunas de las hipótesis sobre la relación cotidiana entre la radio y los sujetos en la organización de la vida doméstica. En la segunda etapa de trabajo de campo, la información proporcionada por las etnografías se cruzó con la obtenida mediante entrevistas cualitativas a los miembros de dos familias seleccionadas en cada grupo de referencia. Las entrevistas fueron de mucha utilidad, porque nos permitieron completar o entender mejor el sentido de las prácticas y rutinas observadas, es decir reconstruir los significados, muchas veces contradictorios, entre "lo que se hace", "lo que se dice que se hace", y lo que se prescribe "debería hacerse". La pauta de entrevista contempló los siguientes bloques temáticos de exploración:

1. Datos biográficos.

2. Hábitos de consumo de la radio (lugares, tiempos, individual o colectivo, situaciones domésticas, etcétera).

3. Preferencias y gustos con respecto a los programas.

4. Motivaciones para escuchar la radio.

5. Ventajas de la radio sobre la televisión y otros medios.

7. La mayoría de los registros resultaron muy buenos y completos en los términos del problema de investigación (no hay que saberlo todo para comprender algo, decía Geertz) y a algunos hubo que desecharlos porque no reunían las condiciones mínimas de una observación de carácter etnográfico (síntesis en lugar de descripción de las rutinas, confusión de lo relevante respecto a lo secundario, etcétera). Previendo esta situación, en cada grupo se contempló la realización de dos registros extras. Para subsanar en parte las lagunas de información encontradas en los registros de campo, se realizaron entrevistas personales con nuestros observadores, con el objeto de solicitar datos adicionales, recabar explicaciones de contexto, y poder interpretar dinámicas afectivas y familiares que aparecían modificando o influyendo en la relación con los medios. 
6. Criterios de selección, valoración, jerarquización y credibilidad de las noticias políticas, económicas, metropolitanas, internacionales, culturales y ecológicas.

7. Criterios para establecer la verdad o falsedad de una noticia, noticiero, periodista o conductor en cada medio (radio, periódico y televisión).

8. Conocimiento, seguimiento y valoración acerca de programas radiales sobre esoterismo, misterios no aclarados y casos sobrenaturales.

9. Conocimiento, seguimiento y valoración acerca de programas de radio sobre asistencia médica, psicológica o sexual.

10. Prácticas y valoración de las diversas formas de participación en la radio (cartas, llamadas, quejas, denuncias, recados, saludos, votaciones, solicitudes de ayuda, consejos, información, etcétera).$^{8}$

\section{Familias y grupos observados}

En ambos periodos de trabajo de campo se seleccionaron 18 familias radioescuchas de distinto nivel sociocultural del Distrito Federal. La condición de ser radioescucha implica que todos los miembros de la familia, o alguno de ellos, consumen con regularidad este medio. El número y las características de las familias se establecieron considerando la composición de los públicos en el Distrito Federal que maneja IBOPE. ${ }^{9}$ El $61 \%$ del consumo radial se ubica en el NSE bajo (C), $29 \%$ en el medio (B) y $9.60 \%$ en el alto (A). Para aproximarnos a esta proporción, se decidió incluir a diez familias en el nivel $\mathrm{C},{ }^{10}$ cinco en el nivel B, y tres en el nivel A. Para elaborar los perfiles de las primeras 18 familias nos basamos en los criterios que utiliza BIMSA (Buró de Investigación de Mercados) en la conformación de sus grupos socioeconómicos. Además de las variables clásicas, como sexo, edad, ocupación, escolaridad, nivel de ingresos, composición familiar y lugar de residencia, se consideran los hábitos y patrones de consumo asociados a las mismas. Esta clasificación, que realizan desde la lógica de la comercialización, con el propósito de estudiar los hábitos de exposición a medios y el consumo de la población, nos resultó muy útil al comienzo para orientar la selección de las familias, asumiendo que el consumo es un indicador importante del universo simbólico y el capital cultural de cada grupo social. En los cuestionarios de BIMSA se indaga sobre el consumo

8. Las entrevistas se realizaron entre febrero y marzo de $1998 \mathrm{en}$ los hogares seleccionados, en algunos casos individualmente y en otros en presencia de otros familiares. En total se realizaron 21 entrevistas de una hora y media en promedio de duración, que posteriormente fueron transcritas para su análisis.

9. Datos de BIMSA proporcionados por la Asociación de Radiodifusores del Valle de México.

10. El nivel $\mathbf{C}$ contempla dos segmentos: el medio-bajo y el bajo. La selección de familias entre los estudiantes de la Universidad Autónoma Metropolitana nos impuso como limitación atender sólo el grupo medio-bajo. 
de medios, uso del tiempo libre, hábitos y lugares de compras, y preferencias acerca de diversos productos, como pastas dentales, desodorantes, cremas limpiadoras, tintes para el cabello, cremas para rasurar, alimentos para perros, pastas para sopas, refrescos, teléfonos celulares, electrodomésticos, cuentas de bancos, limpiadores, antigripales, restaurantes, libros, tarjetas de crédito, centros vacacionales, etc., cuyo comportamiento estudian en relación con la organización de la vida doméstica y las rutinas de la vida cotidiana. La empresa consultora, sin buscarlo ni reconocerlo de este modo, fue reconstruyendo los patrones culturales de consumo de cada grupo social, que ellos denominan "estilos de vida". ${ }^{11}$ Aunque este tipo de clasificación tiene claras limitaciones que surgen de la propia naturaleza de su objeto (describe hábitos y patrones de consumo sin preguntarse ni explorar acerca de los sentidos y significados que estos comportamientos tienen para cada segmento social, ni como éstos se articulan con el sistema económico y social que sustenta sus condiciones de existencia), puede resultar de mucha utilidad para orientar en un primer momento la selección de los grupos y familias en estudios de corte socioantropológico vinculados al consumo.

Luego, para la segunda selección, y como producto de nuestras propias observaciones etnográficas, agregamos a dicha clasificación otros rasgos vinculados a la composición familiar, uso y representación del tiempo y del espacio en diferentes familias, particularmente vinculados al consumo de medios. Estos criterios quedaron agrupados bajo la denominación genérica de nivel sociocultural (NSC en adelante) A, B y C.

Criterios de selección de los periodos de observación etnográfica

Para llevar a cabo el trabajo de campo se seleccionaron dos semanas, la del 21 al 27 de abril de 1997, cuando la agenda de los medios no registró ningún acontecimiento especialmente extraordinario, salvo el asalto por parte del gobierno peruano a la embajada de Japón para la liberación de rehenes, y la previa a las elecciones de Jefe de Gobierno en la Ciudad de México, entre el 2 y el 9 de julio del mismo año. En este periodo las elecciones compitieron en la agenda mediática con las cenizas que se esparcieron por toda la Ciudad de México como producto de la actividad del volcán Popocatépetl. El criterio utilizado fue contrastar la interacción de las familias con el medio en dos situaciones diferentes, una con pocas implicaciones y repercusiones políticas para los ciudadanos, y otra, donde los hechos impactaran significativamente la vida política de la ciudad, con el objeto de corroborar si dichos acontecimientos modificaban las rutinas cotidianas. Se escogió la semana como uni-

\footnotetext{
11. Véase nota 8.
} 
dad de observación porque permitía registrar las rutinas a lo largo de la semana y los fines de semana. Se privilegió como horario de observación el segmento comprendido entre el momento de levantarse por la mañana y el final del desayuno antes de la salida de la casa, porque en indagaciones previas se comprobó que se trata de un segmento clave por las siguientes razones: a) coincide con el pico más alto de la curva de encendido; b) por lo general la radio está encendida cuando toda la familia se sienta a desayunar, lo cual permite registrar las interacciones de cada miembro con el medio y, a la vez, entre ellos; c) es la hora del noticiero.

Estrategia de análisis para el material etnográfico

Para comprender la presencia y el vínculo con la radio en el contexto doméstico trazamos un mapa de posibilidades que básicamente permiten cruzar tres perspectivas de análisis:

a) Establecer modalidades de interacción y apropiación comunes, independientemente de la pertenencia sociocultural de los hogares estudiados.

b) Caracterizar las prácticas y apropiaciones simbólicas según pertenencia e identidad socio-cultural.

c) Ídem, pero teniendo en cuenta audiencias diferenciadas según sexo y edad.

Como ya se especificó, combinamos el registro etnográfico de las rutinas, hábitos y modos de apropiación del discurso radial en el ámbito doméstico con las entrevistas en profundidad a los miembros de las familias estudiadas. La combinación de estas fuentes de información nos permitió enriquecer considerablemente la interpretación de los datos y aproximarnos en forma más abarcadora al objeto de estudio.

Para dar cuenta de las lecturas preferenciales consideramos el esquema de Morley (1996) que, siguiendo a Parkin (1971), propone una clasificación según la cual los miembros de las diferentes clases sociales comparten "sistemas de sentido" o marcos ideológicos que funcionan en el momento de la decodificación. Parkin afirma que en las sociedades occidentales existen tres sistemas de sentido principales, cada uno de los cuales procede de una fuente social diferente y posee una interpretación moral distinta sobre la desigualdad de clases. Si adaptamos esta clasificación a la lectura de los medios, tenemos tres posibilidades que en principio nos ofrecen tres marcos interpretativos para analizar la decodificación de los mensajes:

a) Que el sujeto acepte plenamente el sentido propuesto por la lectura preferencial y el código dominante que ofrece el mensaje.

b) Que el sujeto se apropie en términos generales del sentido dominante del mensaje, pero que lo cambie en parte o totalmente cuando hace referencia a contextos y situaciones propias; ésta sería una posición "negociada" en términos de Parkin. 
c) Que el sujeto ponga en entredicho tanto el marco interpretativo como el contenido del mensaje y, en este caso, se ubique en franca oposición.

Hay que señalar que, aunque esta distinción, sobre todo al comienzo del análisis, resulta útil para tratar de organizar un mapa de decodificaciones, en la práctica y particularizando en nuestro material de campo, dentro de cada grupo de referencia se presentaron varias situaciones: frente a ciertos mensajes se pudieron establecer lecturas preferenciales, en otros aparecieron lecturas más ambiguas o se presentaron diversos cruces de lecturas negociadas a partir de diferencias de género o generacionales.

\section{Los programas estudiados}

Para abordar el otro problema que nos preocupaba, la reconstrucción de la lógica de producción de los discursos radiales, tomamos como unidad de observación y análisis a diversos programas y sus participantes para entender, por una parte, las posibilidades de inclusión de los ciudadanos en la esfera pública mediática y, por otra, el papel que desempeña esta participación en la transformación del sentido de lo público y lo privado.

A lo largo de cinco años se dio seguimiento a diversos programas, pero no todos se trabajaron con la misma profundidad y los mismos objetivos. Concentramos más nuestra atención en los noticieros, programas de opinión pública y consultorios sentimentales, porque como unidades de análisis respondían más claramente al objeto de investigación. En virtud de lo anterior, la selección de programas no siguió un patrón determinado. En algunos casos el criterio fue la antigüedad, en otros el rating, el tipo de propuesta, el público al que iba dirigido, o el tipo de participación de los radioescuchas. ${ }^{12} \mathrm{El}$ trabajo de sistematización de la información consistió en:

1. Grabación, transcripción y análisis de un número variable de emisiones.

2. Entrevistas en profundidad a locutores y productores.

3. Entrevistas en profundidad a participantes de los programas Ke buena está la mañana y Voz pública. ${ }^{13}$

12. Algunos segmentos como Monitor de Radio Red y Buenos días fueron trabajados con mayor detenimiento, otros programas fueron incluidos sólo como referencia o para ilustrar algún punto en particular. En consecuencia, el tiempo de monitoreo varió considerablemente. En el caso de Monitor de Radio Red, Voz pública de Radio educación, y Buenos días de Radio Fórmula, se grabaron entre una y dos semanas de emisiones; en los consultorios sentimentales y de asistencia psicológica (Parejas disparejas, Fallaste corazón, Pregúntale a Emi y Desnudo total), entre dos y cinco días. Del programa dirigido a homosexuales, Medianoche en Babilonia, se grabaron cuatro emisiones a lo largo de un mes y del resto de los programas citados, sólo un día de emision.

13. Las entrevistas provienen de varias fuentes; algunas fueron realizadas por mis alumnos de la carrera de Comunicación Social de la Universidad Autónoma Metropolitana, otras por los becarios del Proyecto Conacyt ya citado, para sus respectivas tesis, y otras las realicé 
Estrategias de análisis para los programas y radioparticipantes

En el análisis de las entrevistas y los programas se dio prioridad a la reconstrucción de los significados, recuperando por una parte la perspectiva del medio en la lógica de construcción del acontecimiento, y por otra, el sentido que tiene la participación tanto para los que llaman como para los que integran redes telefónicas, forman grupos de autoayuda o simplemente escuchan.

En el caso de los programas, particularmente en los noticieros, construimos dos miradas para dar cuenta de su papel en lo que hemos denominado "domesticación de la ciudad". En primer término los abordamos como una narrativa sobre la ciudad, y clasificamos recursos como el uso de las metáforas, las citas y el lenguaje coloquial, para la creación o recreación de mitos y estereotipos sobre el poder, las autoridades, la convivencia, los estilos de vida y las relaciones sociales en la ciudad. En segundo lugar, analizamos el contenido de los discursos, con el objeto de categorizar los recursos y estrategias que utilizan los conductores para validar sus comentarios y caracterizar a los ciudadanos: consulta de expertos, el uso de testimonios de los protagonistas, la participación del radioescucha y la cobertura de los hechos en vivo, por citar algunos. También sistematizamos las formas de caracterización e interpelación a los ciudadanos.

En este caso interesaba reconstruir la lógica del acontecimiento mediático desde la perspectiva de sus productores. Para reconstruir la lógica inversa, es decir la perspectiva de los radioparticipantes, se diseñó una entrevista con el objeto de caracterizar las formas y modalidades de participación según el uso y el sentido que los participantes de distinta pertenencia sociocultural dieran a distintos segmentos y géneros programáticos. ${ }^{14}$

personalmente en función de las necesidades que planteó el problema de investigación. El número de entrevistas también varió considerablemente por programa. En total se efectuaron más de 50 entrevistas a conductores, productores, radio-participantes y líderes de grupos de autoayuda.

14. Los bloques temáticos para las entrevistas a radioparticipantes y líderes de grupos de autoayuda que luego se convirtieron en variables de análisis fueron los siguientes: a) datos biográficos; b) hábitos de escucha y preferencias programáticas; b) experiencia de participación; c) motivaciones para participar; d) valoración y uso de otras instancias de canalización de demandas públicas y privadas; e) percepción de las instituciones y funcionarios públicos; $f$ percepción del papel que juegan los medios en la canalización, traducción o solución de sus demandas. 


\section{Para concluir: el aporte de la etnografía para la comprensión situada de los públicos}

Los medios, en su doble carácter de texto y tecnología, están indisolublemente unidos con las prácticas cotidianas y la organización de la vida doméstica. Si queremos dar cuenta de la significación de estos vínculos, debemos considerar el proceso de comunicación en el lugar y en el momento donde se realiza. La comprensión del sentido social que adquiere el consumo de la radio o la televisión pasa por desentrañar las reglas que estructuran cotidianamente la circulación y resignificación de los mensajes en diferentes grupos sociales. Las técnicas más populares de medición de auditorios en hogares (encuestas puerta a puerta, sondeos telefónicos, instalación de aparatos en los televisores, etc.), aíslan al sujeto de la situación donde el consumo ocurre naturalmente, tan sólo se limitan a constatar que en determinados horarios diferentes miembros de la familia encienden sus televisores y se exponen con cierta regularidad a la programación de su agrado. Sin embargo, el acto de encender el televisor o el radio puede significar muchas cosas, desde "ya llegué a casa", "necesito compañía", "no quiero escuchar la pelea del vecino", o "ya es hora de ir a buscar a los niños a la escuela". Como señala Silverstone (1996), la televisión no sólo es parte de la vida cotidiana, sino que es vida cotidiana, no podemos estudiar una sin la otra. Concebir el consumo en la perspectiva expuesta nos obliga a situar su estudio en el ámbito doméstico y de la vida cotidiana. Esto plantea lógicamente la necesidad de incorporar la perspectiva etnográfica como estrategia metodológica y principio para abordar la realidad.

Un enfoque etnográfico e interdisciplinario del estudio de la comunicación (Morley, 1996: 264) nos posibilita "entender cómo los propios actores sociales definen y comprenden sus prácticas de comunicación (sus decisiones, sus elecciones y las consecuencias que éstas tienen en su vida cotidiana y en sus acciones posteriores)". Las ventajas que ofrece este enfoque no sólo residen en la comprensión, a partir de la recuperación de la perspectiva del actor, ${ }^{15}$ del sentido de las prácticas de interacción con los medios, sino de su capacidad para explicar cómo los hábitos y preferencias individuales se integran en la dinámica de la vida familiar y en la organización del espacio doméstico, y, a su vez, expresan el habitus de cada grupo social:

15. Entendemos la perspectiva del actor como "universo de referencia compartido - no siempre verbalizable - que subyace y articula el conjunto de prácticas, nociones y sentido organizados por la interpretación y actividad de los sujetos sociales" (Guber, 1991: 75). En el entramado significante de la vida social los sujetos tornan inteligible el mundo en que viven, a partir de un saber compartido - aunque desigualmente distribuido y aplicado-que incluye experiencias, necesidades, posición social, modelos de acción e interpretación, valores, normas" (Guber, 1991: 74). 
la cuestión no es sólo pragmática; no se trata sólo de establecer la parte (o los elementos del contexto) que se necesita para llegar a comprender cualquier acto; es también una cuestión teórica y (epistemológica) sobre la relación entre lo particular y lo general, entre el caso aislado y la categoría (Morley, 1996: 270).

Asimismo, una etnografía crítica no sólo permite explorar la diversidad de las prácticas locales de consumo respecto a la homogeneidad de los flujos globalizados, sino que puede "clarificar la dialéctica compleja de la diversidad y de la homogeneidad" (Lull, 1997). De ahí la importancia de reconstruir el ámbito doméstico no sólo como el contexto donde se escucha la radio, sino como el espacio físico y simbólico que estructura de manera fundamental el conjunto de prácticas y representaciones cotidianas que intervienen en el consumo mediático, y también como el lugar donde se integran comunidades imaginarias de pertenencia y se trasciende a la escena pública.

En síntesis, el enfoque etnográfico nos sitúa en el contexto familiar de recepción para indagar en términos de apropiación simbólica qué hace la gente con la radio, cómo decodifica los mensajes, y cómo esta experiencia de interacción cotidiana articula la dimensión de lo local con lo global, el ámbito privado con lo público y la esfera doméstica con el poder.

\section{Bibliografía}

Ang, I. (1997), "Cultura y comunicación. Hacia una crítica etnográfica del consumo de los medios en el sistema mediático transnacional", en Daniel Dayan (comp.), En busca del público, Barcelona, Gedisa.

Borja, J. y M. Castells (1998), Local y global. La gestión de las ciudades en la era de la información, Madrid, Taurus.

Bourdieu, P. (1998), La distinción, Madrid, Taurus.

Dayan D. (1997), "Relatar al público", en Daniel Dayan (comp.), En busca del público, Barcelona, Gedisa.

Douglas M. y B. Isherwood (1990), El mundo de los bienes. Hacia una antropología del consumo, México, Grijalbo-CNCA.

García Canclini, N. (1995), Consumidores y ciudadanos, México, Grijalbo.

González J. (1994), Más(+) cultura(s). Ensayos sobre realidades plurales, México, Conaculta.

Guber, R. (1991), El salvaje metropolitano, Buenos Aires, Legasa.

Hall, S. (1974), "Deviancy, Politics and the Media", en P. Rock y M. McIntosh (eds.), Deviance and Social Control, Londres, Tavistock.

- (1989), Cultural Identity and Cinematic Representation, Framework, 36. 
Lull, J. (1997), Medios, comunicación, cultura, Buenos Aires, Amorrortu.

Martín-Barbero, J. (1993), De los medios a las mediaciones, Barcelona, G. Gili. (1997), "De los medios a las culturas", en J. Martín Barbero y A. Silva (comps.), Proyectar la comunicación, Bogotá, Tercer Mundo Editores, pp. 3-22.

(1999), "El miedo a los medios. Política, comunicación y nuevos modos de representación", en Nueva Sociedad, núm. 161, mayo-junio, Caracas, pp. 43-56.

Mata, C. (1992), "Entre la plaza y la platea", en Política y Comunicación, Córdoba.

Mattelart, A. (1987), Pensar sobre los medios, Madrid, Fundesco.

Morley, D. (1996), Televisión, audiencias y estudios culturales, Buenos Aires, Amorrortu.

Orozco, G. (coord.) (1994), “Televidencia. Perspectivas para el análisis de los procesos de recepción televisiva", en Cuadernos de Comunicación y Prácticas Sociales, México, Universidad Iberoamericana, núm. 6.

Parkin, F. (1971), Class Inequality and Political Order, Londres, Paladin.

Silverstone, R. (1996), Televisión y vida cotidiana, Buenos Aires, Amorrortu.

Verón E. (1983), Construir el acontecimiento, Barcelona, Gedisa.

Winocur, R. (2002), Ciudadanos mediáticos. El papel de la radio en la construcción de lo público, Gedisa (en prensa). 